\title{
Successful Propranolol Treatment of Multiple Infantile Hemangiomas with Predominant Neuroaxial Involvement: a Case Report
}

\section{Hemangioma múltiplo da infância com envolvimento predominantemente neuroaxial tratado com propranolol: relato de caso}

\author{
Angela F. de A. Bocchese ${ }^{1}$ Gregori Manfroi ${ }^{1,2}$
Fábio P. Santos ${ }^{6}$
${ }^{1}$ School of Medicine, Universidade de Passo Fundo (UPF), Passo \\ Fundo, RS, Brazil \\ 2 Liga Acadêmica do Serviço de Neurologia e Neurocirurgia, Hospital \\ da Cidade de Passo Fundo, Passo Fundo, RS, Brazil \\ 3 Department of Neurosurgery, Hospital da Cidade de Passo Fundo, \\ Passo Fundo, RS, Brazil \\ ${ }^{4}$ School of Medicine, Instituto Meridional (IMED), Passo Fundo, RS, \\ Brazil \\ ${ }^{5}$ Pediatric Oncologist, Associate Professor at the UPF, Passo Fundo, \\ RS, Brazil \\ ${ }^{6}$ Otolaryngologist, Associate Professor at the UPF, Passo Fundo, RS, \\ Brazil
}

Arq Bras Neurocir 2016;35:169-173.

\author{
Address for correspondence Angela Bocchese, Medical Student, \\ Hospital São Vicente de Paulo, Rua Coronel Chicuta 30/304, Passo \\ Fundo, RS, Brazil (e-mail: angelaboc@gmail.com).
}

\author{
Abstract \\ Keywords \\ - hemangioma \\ - infantile \\ - vascular neoplasm \\ - neonate \\ - central nervous \\ system \\ - propranolol
}

Infantile hemangiomas $(\mathrm{IH})$ are the most common vascular tumor of infancy. Occurrences during the neonatal period are divided in multiple congenital, limited to skin involvement, or diffuse neonatal hemangiomatosis (DNH). DNH is considered to be a benign and rare disease, determined by the presence of multiple cutaneous and extracutaneous hemangiomas. The encephalic and medullary involvement of $\mathrm{IHs}$ is unusual and rarely reported. The authors report a case of infantile hemangioma (IH) as diffuse neonatal hemangiomatosis with predominant central nervous system involvement on a neonate, treated with propranolol. We discuss the use propranolol as main therapy and review the available data regarding $\mathrm{IH}$ s with neuroaxial involvement and its treatment. received

November 9, 2015 accepted January 19, 2016 published online April 14, 2016
DOI http://dx.doi.org/ 10.1055/s-0036-1581083. ISSN 0103-5355.
Copyright $@ 2016$ by Thieme Publicações License terms

Ltda, Rio de Janeiro, Brazil 


\section{Resumo}

\section{Palavras-chave}

- hemangioma

- infância

- tumor vascular

- neonato

- sistema nervoso central

- propranolol
Hemangiomas da infância (HI) são o tipo mais comum de tumores vasculares nessa faixa etária, e, quando no período neonatal, podem ser divididos em múltiplos congênitos, limitados ao envolvimento cutâneo, ou hemangiomatose neonatal difusa (HND). A HND é considerada uma doença rara e benigna, determinada pela presença de múltiplos hemangiomas cutâneos e extracutâneos. O envolvimento encefálico e medular nos $\mathrm{HI}$ é incomum e raramente reportado. Relatamos um caso de hemangioma da infância na forma de hemangiomatose neonatal difusa com acometimento predominante do sistema nervoso central tratado com propranolol em neonato. São discutidos o uso de propranolol como terapia de escolha e a revisão de literatura sobre $\mathrm{HI}$ com envolvimento neuroaxial e sua terapêutica.

\section{Introduction}

Infantile hemangiomas $(\mathrm{IH})$ are the most common vascular tumor of infancy, usually presenting at birth or during the first few months of life. ${ }^{1}$ When on neonatal period, it can be divided into two different classifications: multiple congenital, limited to skin involvement, or as a potentially fatal condition called diffuse neonatal hemangiomatosis (DNH). ${ }^{2}$ $\mathrm{DNH}$ is considered a rare disease, histologically benign, and determined by the presence of multiple cutaneous and extra-cutaneous hemangiomas fairly distributed throughout the body and that may be found in any organ. ${ }^{3}$ The prevalence of neuroaxial involvement by $\mathrm{IH}$ is extremely low, and the predominant central nervous system (CNS) involvement is described, but rarely reported., ${ }^{45}$ DNH lesions, like all IHs, usually proliferate initially until eventually they involute. However, extra cutaneous involvement may result in lifethreatening conditions. DNH has a high mortality rate, which can be significantly reduced with early diagnosis and appropriate treatment. Management should be directed to specific clinical manifestations and multiple therapies are available. Systemic corticosteroids used to be the first-line treatment for $\mathrm{IH}$; however, long term use can lead to serious side effects such as hypertension, adrenal cortical insufficiency, and delay of growth. ${ }^{6}$ Since 2008, propranolol, a non-selective $\beta$-blocker was found to be an effective alternative for treatment of IH. We describe the case of a neonate that received propranolol as main therapy, and review the available data regarding IH with neuroaxial involvement and its treatment.

\section{Case Report}

A 2-month-old male infant was referred for paralysis of the left upper limb, of sudden onset, 20 days after birth. He also presented multiple dark, purple, nodular cutaneous lesions on frontal, frontoparietal, and occipital regions, right nasal ala, right forearm, and torso since birth, painless and that grew progressively in size (-Fig. 1). After admission, he presented difficulty while breastfeeding, accompanied by nasal rhonchi and trouble breathing. From his medical history, he was born at 38 weeks of gestation, via uncomplicated cesarean delivery from a 40 -year-old woman. At physical examination, complete obstruction of right nostril by vegetative, friable mass with hyperemia was noted, along with an additional external $2 \mathrm{~mm}$ lesion on right nasal ala. There were also small purple papules on the right forearm, anterior dorsum, torso, and on both occipital and frontal regions. At neurological examination, the infant was alert and irritated, with pupils equally photoreactive, and presented spastic paralysis of left upper limb, determining asymmetric Moro reflex. All other limbs had preserved mobility and strength. Abdominal ultrasound was normal, but the Thoracic Computed Tomography (CT) demonstrated an expansive lesion on the left lung suggestive of hemangioma. At the abdominal CT, a bone lesion at the right hip was also compatible with hemangioma. A brain Magnetic Resonance Imaging (MRI) evidenced multiple lesions (-Fig. 2), both supra and infratentorial, compatible with hemangiomas. Particularly, the lesions located on the left side of the cervical spinal cord and on the right side of the cerebral peduncle might be responsible for the spastic paralysis of the left upper limb.

We performed excisional biopsies of two of the skin papules and confirmed the histological diagnosis of hemangioma. Laboratory findings showed normochromic and normocytic anemia, elevated bilirubin, and LDH (lactate dehydro genase). We initiated corticosteroids with later dosage titration, before starting $2 \mathrm{mg} / \mathrm{kg} /$ day of propranolol. During the $\beta$-blocking therapy, there were no significant adverse effects. After 8 months, we observed significant reduction or complete resolution of cutaneous lesions. On follow-up MRI, there was clear evidence of regression of the majority of CNS lesions. Also, partial restoration of mobility and strength in the left upper limb occurred. The right nasal obstruction had almost complete regression. Thoracic CT scan showed apparent progression of the pulmonary lesion that could be related to natural organ growth. The child's growth and psychomotor development were normal.

\section{Discussion}

Infantile hemangiomas, especially when cutaneous, are the most common tumor of infancy, affecting 1 to $2 \%$ of neonates. They tend to be more frequent in females and prematures, and usually present in the first weeks of life, having a characteristic evolution. Most commonly, vascular tumors 

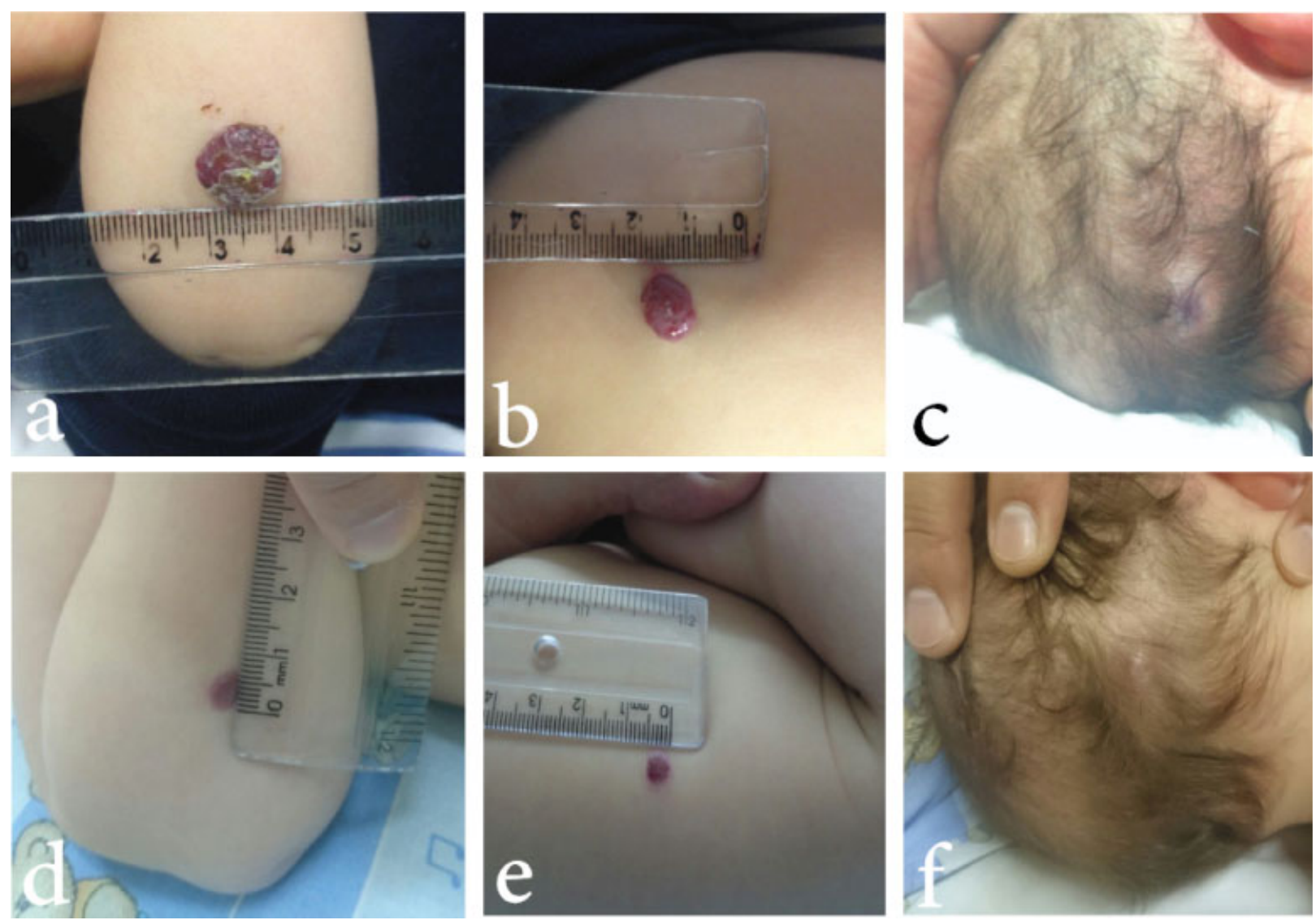

Fig. 1 Multiple dark, purple, nodular cutaneous lesions on frontal, frontoparietal, and occipital regions, right nasal ala, right forearm, and torso. Before propranolol treatment $(a, b, c)$, and after $(d, e, f)$.

go through a growth period (proliferative phase), reaching a plateau usually at 9 to 10 months of age (stability phase), following spontaneous regression (involution)., ${ }^{4,7}$ Diffuse neonatal hemangiomatosis (DNH) is a type of IH characterized by the involvement of at least three separate organs, in addition to those of the skin, and may present as a severe, life-threatening disorder, with much higher morbidity and mortality rates. 3,8

DNH is an uncommon and frequently fatal disorder that occurs on $1-2.6 \%$ of term infants, with a typical onset at birth or during the first month of life. It is usually associated with a poor prognosis, although malignant transformation is rare. Apart from the skin, which is always involved, the liver is the most common extracutaneous site (64-100\%), but any other organ can be affected. ${ }^{3}$ The prevalence of neuroaxial involvement by IHs is extremely low and there are only few cases of true intracranial lesions reported and even fewer on the cervical spinal cord, as reported in the described case. ${ }^{4}$ When it does occur, there is a predilection for the posterior fossa, especially the fourth ventricle and the cerebellopontine angle cistern. Other reported sites include the pineal region, hypothalamus, hippocampus, and the cerebellar convexity. Nevertheless, diffuse CNS involvement is considered rare. ${ }^{4}$

The differential diagnosis of vascular lesions involving the neuraxis in infancy includes hemangioma, hemangioblastoma (including von Hipple-Lindau disease), vascular malformations, and other neonatal tumors, such as soft-tissue sarcoma. We considered Von Hipple-Lindau (VHL) disease during diagnostic investigation due to the presence of multiple benign cutaneous tumors and multiple CNS lesions. However, it was later ruled out due to the absence of other clinical characteristics related to the disease, such as retinal and CNS hemagioblastomas and renal cell carcinoma. ${ }^{9}$ Skin biopsies confirming the presence of hemangiomas also made the VHL diagnose less likely. Through the CT, it was possible to differentiate hemangiomas from hemangioblastomas. The presence of a radiologically indistinguishable extracranial tumor and concordant changes in size of the extra-CNS and CNS lesions suggest neuroaxial hemangioma. In contrast, hemangioblastomas often have a cyst with an associated enhancing nodule. ${ }^{4}$

Clinical manifestations can be variable and dependent on the site and size of the hemangioma. Skin lesions are frequently multiple, ranging from $2 \mathrm{~mm}$ to $2 \mathrm{~cm}$, with violet-red or blue color, present at birth or that have evolved during the neonatal period. ${ }^{8}$ Like isolated ones, the hemangiomas from DNH proliferate and then involute, but extracutaneous involvement may evolve to life-threatening complications and are associated with a high rate of mortality (between 50 and $90 \%)^{3,10}$ Death is usually due to congestive heart failure, as a result of an increased cardiac output caused by AV shunting in the liver, but can also occur due to hemorrhage, gastrointestinal and cutaneous bleeding. 

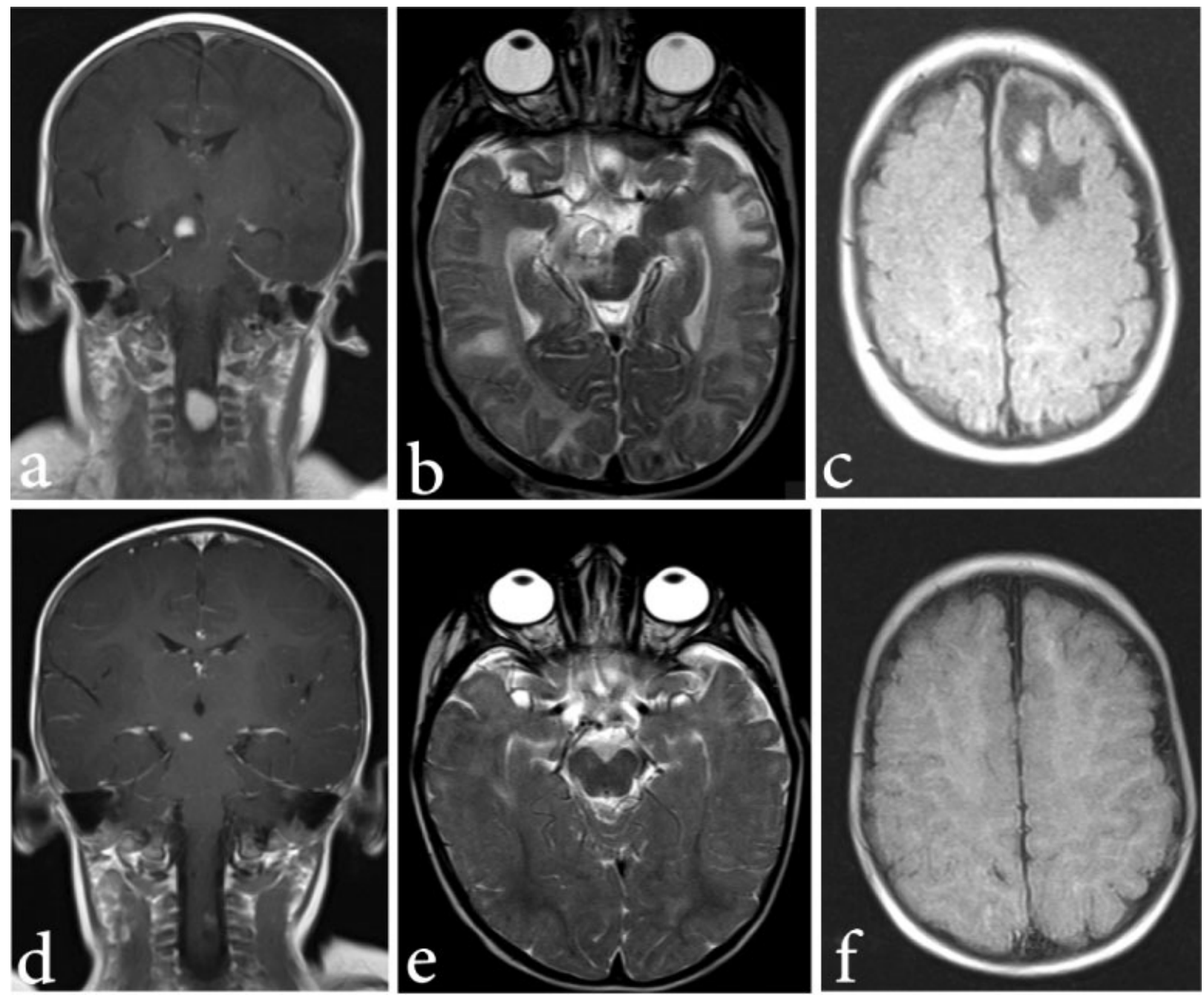

Fig. 2 Brain Magnetic Resonance Imaging (MRI) evidenced multiple lesions. Before $\beta$-blocking therapy (a,b,c) and after (d,e,f).

The pathogenesis of the IH is not yet fully understood, but it is considered to be a result of an imbalanced angiogenesis, allowing uncontrolled proliferation of vascular elements. ${ }^{7}$ Masses of rapidly dividing endothelial cells with or without lumen and a multilaminated basement membrane are formed while on proliferating phase. During the involution phase, the lumen dilates, the endothelial cells thin, and fibrous tissue are deposited. Immunohistochemical studies show expression of CD31, von Willebrand factor, and other proteins, which suggest a proliferative vascular origin. ${ }^{3}$

Due to its frequent rapid progression, early intervention is necessary either to avoid progression or to induce regression. Mortality rate is $27 \%$ with adequate treatment, while $77 \%$ without any therapy. The objective of the treatment is to speed-up the process of involution, reducing fatal complications. ${ }^{10}$ Multiple therapies are available and well documented, including corticosteroids, vinca alkaloids, cyclophosphamide, alfa-interferon and, most recently, propranolol. ${ }^{11}$ Nonpharmacological options include the use of radiation, embolization, and surgical resection, although with higher rates of complications.

For more than three decades, corticosteroid therapy, either topical, intralesional, or oral, have been the mainstay for treating IHs, with initial recommended dose of $2-3 \mathrm{mg} /$ $\mathrm{kg} /$ day. Corticosteroids therapy is associated with insidious side effects frequently difficult to control, like hypertension, growth retardation, Cushing's syndrome, and increased susceptibility to infection. ${ }^{12}$ However, up to $30 \%$ do not respond and other second-line options like systemic interferon, vincristine, and surgery might be necessary. ${ }^{13}$

The effect of the oral-betablocker propranolol in $\mathrm{IH}$ is promising. It was first suggested in 2008, when LéautéLabreze et $\mathrm{al}^{14}$ reported incidental findings that hemangiomas regress in children treated with propranolol. ${ }^{15}$ Peridis et $\mathrm{al}^{16}$ meta-analysis analyzed the effectiveness of propranolol versus steroids, $\mathrm{CO}_{2}$ laser, or vincristine for the treatment of airway IHs. They demonstrated that propranolol is the most effective treatment as compared with others. ${ }^{16}$ It is unclear how propranolol affects growth and involution of $\mathrm{IH}$ and whether the same mechanisms of action are involved in proliferative and post-proliferative phases, but it is thought to act diminishing the expression of the vascular endothelial factor (VEGF) and the basic fibroblast growth factor (bFGF), triggering endothelial apoptosis. ${ }^{13}$ Its use hinders tumor growth and, at the same time, promotes volumetric decrease of the lesion in a more constant rate than corticoids. 
Several studies have confirmed that oral propranolol significantly accelerates the involution rate of $\mathrm{IH}$, even in post-proliferative phases, in children up to 10 years of age. ${ }^{6,12,13,17}$ According to Hogeling, with an initial dose of $0.17 \mathrm{mg} / \mathrm{kg}$ administered every 8 hours and its gradual increase to up to $0.67 \mathrm{mg} / \mathrm{kg} /$ dose, ${ }^{7,17}$ it was possible to observe the effect of propranolol early in the treatment, ${ }^{17}$ the first effects appearing in the first hours with changes in color and softening of the lesions. ${ }^{18}$ With less than four weeks of treatment, growth abruptly stopped ${ }^{17}$ and during follow-up, there was significant decrease in size. ${ }^{15}$ Review of literature indicated that, despite the efficacy of propranolol in the majority of the patients with $\mathrm{IH}$, treatment modalities other than propranolol were still just starting.

According to a case report by Miquel et al, ${ }^{19}$ there are only five cases reported of CNS disease in multiple IHs: two were treated with corticosteroids (with neurologic sequelae and side effects), two were treated with surgical excision, and only one was effectively treated with propranolol. On the reported case, propranolol was used to treat multiple cerebral and spinal hemangiomas, with rapid improvement by day 45 and disappearance of lesions on neuroimaging at 6 months. ${ }^{19}$ Therefore, there is little evidence on the literature regarding the efficacy of $\beta$-blocking therapy as main therapy for IHs involving the neuraxis. The majority of data on IH treatment only evaluates the effect of propranolol on cutaneous lesions. Propranolol is a lipophilic $\beta$-blocker, thus, it easily penetrates the blood-brain barrier. It is important to note, though, that lipophilicity of the drug may not directly correspond to effects exerted in the brain. ${ }^{20}$

The optimal dose and duration of propranolol therapy remains to be investigated. ${ }^{6}$ The most effective duration of treatment is not well documented, and early discontinuation during the proliferative phase was associated with an increased risk of recurrence. ${ }^{12}$ In addition, patients that have received other treatments did not respond as well to propranolol treatment. ${ }^{17}$ Adult studies documented potential propranolol CNS-related adverse effects, such as impaired short- and long-term memory, psychomotor function, sleep quality, and mood, that may have significance for pediatrics. A recent systematic review of propranolol in IHs described sleep disturbances (including fatigue, insomnia, nightmares, and restlessness) as the most common adverse effect. ${ }^{20}$ Notwithstanding, there is no documented case of death or serious cardiovascular morbidity resulting directly from $\beta$-blocker therapy; however, well-known side effects, such as bradycardia and hypotension, should be monitored at the onset of treatment. ${ }^{18}$ Thus, propranolol can be considered a safe and effective treatment for infantile hemangiomas, ${ }^{6,17}$ with satisfactory permanent results and fewer adverse effects than corticosteroids. $^{6,7}$

\section{Conclusion}

Infantile hemangiomas with CNS disease is exceptional and, in the reviewed literature, there were only few cases reported using propranolol as first-line treatment. Our case with multiple cerebral and spinal hemangiomas was successfully treated with propranolol and showed rapid improvement on both clinical status and imaging, with no impairing side effects. The progression presented was similar to that observed in literature. Thus, $\beta$-blocking therapy should be considered also for treating CNS lesions, even in neonates.

\section{References}

1 Gontijo B, Silva CMR, Pereira LB. Hemangioma da infância. An Bras Dermatol 2003;78(6):651-673

2 Mulliken JB, Glowacki J. Hemangiomas and vascular malformations in infants and children: a classification based on endothelial characteristics. Plast Reconstr Surg 1982;69(3):412-422

3 Maya J. Gerardo Blanco, Rocío Maldonado. Diffuse neonatal hemangiomatosis. Bol Med Hosp Infant Mex 2013;70(1):35-40

4 Viswanathan V, Smith ER, Mulliken JB, et al. Infantile hemangiomas involving the neuraxis: clinical and imaging findings. AJNR Am J Neuroradiol 2009;30(5):1005-1013

5 Al-Kaabi A, Yanofsky R, Bunge M, Hyman J, Rafay MF. Diffuse hemangiomatosis with predominant central nervous system involvement. Pediatr Neurol 2009;40(1):54-57

6 Liu X, Qu X, Zheng J, Zhang L. Effectiveness and Safety of Oral Propranolol versus Other Treatments for Infantile Hemangiomas: A Meta-Analysis. PLoS ONE 2015;10(9):e0138100

7 Bonini FK, Bellodi FS, Souza EM. Propranolol treatment for hemangioma of infancy. An Bras Dermatol 2011;86(4):763-766

8 Metry DW, Hebert AA. Benign cutaneous vascular tumors of infancy: when to worry, what to do. Arch Dermatol 2000;136(7):905-914

9 Albiñana V, Villar Gómez de Las Heras K, Serrano-Heras G, et al. Propranolol reduces viability and induces apoptosis in hemangioblastoma cells from von Hippel-Lindau patients. Orphanet J Rare Dis 2015;10(1):1-12

10 Patiroglu T, Sarici D, Unal E, et al. Cerebellar hemangioblastoma associated with diffuse neonatal hemangiomatosis in an infant. Childs Nerv Syst 2012;28(10):1801-1805

11 Drolet BA, Frommelt PC, Chamlin SL, et al. Initiation and use of propranolol for infantile hemangioma: report of a consensus conference. Pediatrics 2013;131(1):128-140

12 Broeks IJ, Hermans DJJ, Dassel ACM, van der Vleuten CJM, van Beynum IM. Propranolol treatment in life-threatening airway hemangiomas: a case series and review of literature. Int J Pediatr Otorhinolaryngol 2013;77(11):1791-1800

13 Zvulunov A, McCuaig C, Frieden IJ, et al. Oral propranolol therapy for infantile hemangiomas beyond the proliferation phase: a multicenter retrospective study. Pediatr Dermatol 2011;28(2):94-98

14 Léauté-Labrèze $C$, Dumas de la Roque E, Hubiche T, Boralevi F, Thambo J-B, Taïeb A. Propranolol for severe hemangiomas of infancy. N Engl J Med 2008;358(24):2649-2651

15 Xiao Q Li Q, Zhang B, Yu W. Propranolol therapy of infantile hemangiomas: efficacy, adverse effects, and recurrence. Pediatr Surg Int 2013;29(6):575-581

16 Peridis S, Pilgrim G, Athanasopoulos I, Parpounas K. A metaanalysis on the effectiveness of propranolol for the treatment of infantile airway haemangiomas. Int J Pediatr Otorhinolaryngol 2011;75(4):455-460

17 Hogeling M, Adams S, Wargon O. A randomized controlled trial of propranolol for infantile hemangiomas. Pediatrics 2011;128(2): e259-e266

18 Sans V, de la Roque ED, Berge J, et al. Propranolol for severe infantile hemangiomas: follow-up report. Pediatrics 2009; 124(3):e423-e431

19 Miquel J, Bruneau B, Dupuy A. Successful treatment of multifocal intracerebral and spinal hemangiomas with propranolol. J Am Acad Dermatol 2014;70(4):e83-e84

20 Langley A, Pope E. Propranolol and central nervous system function: potential implications for paediatric patients with infantile haemangiomas. Br J Dermatol 2015;172(1):13-23 